\title{
EDUCAÇÃO NO ASILO DOS EXPOSTOS DA SANTA CASA EM SÃO PAULO: | 896-1950
}

\author{
MOYSÉS KUHLMANN JÚNIOR \\ Departamento de Pesquisas Educacionais da Fundação Carlos Chagas \\ Universidade São Francisco \\ moyses@saofrancisco.edu.br
}

JOSÉ FERNANDO TELES DA ROCHA

Mestre em Educação pela Universidade São Francisco

jftr36@hotmail.com

\begin{abstract}
RESUMO
Este texto pretende identificar aspectos da educação das crianças de zero a seis anos, no Asilo dos Expostos da Santa Casa de Misericórdia de São Paulo, de 1896 até 1950. Para tanto, foram consultados os Relatórios dos Mordomos dos Expostos. O texto trata inicialmente das propostas para os bebês, e posteriormente das propostas para as crianças de três a seis anos. Em relação aos bebês, o aspecto mais importante foi o fato de as crianças não serem mais entregues às amas para serem criadas, permanecendo no berçário, que foi fundado em 1936. Com relação às crianças maiores, desde o início do século identifica-se a existência do jardim-de-infância, que irá também se renovar na década de 1940, com a chegada de profissionais ligadas à secretaria estadual de educação. As propostas e as concepções pedagógicas existentes na sociedade se manifestam nas funções educacionais do asilo. EDUCAÇÃO INFANTIL - CRIANÇAS - HISTÓRIA DA EDUCAÇÃO - PEDAGOGIA
\end{abstract}

\section{ABSTRACT}

EDUCATION AT SANTA CASA ASYLUM OF THE DISPLAYED IN SÃO PAULO: 1896 1950. This text intends to identify educational aspects of zero to six years old children, in the Asylum of the Displayed of São Paulo Santa Casa de Misericórdia, from 1896 up to 1950. For such, reports of the butlers of the House of the Displayed had been consulted. The text deal, initially, with the proposals for the babies and, later, with those for the three to six years old

Versão preliminar deste texto foi aprovada para reunião da Associação Brasileira de Pesquisa em Educação - Anped -, como excedente, no Grupo de Trabalho História da Educação. 
children. With regard to the babies, the most important issue was the fact that the children were no longer given to be raised by wet nurses: they remained in the nursery, which was created in 1936. In relationship to older children, the pre-school, founded in the beginning of the century, was renewed in the decade of 1940, with the arrival of professionals linked to the state board of education. The existing proposals and pedagogical conceptions of society are disclosed in the educational functions of the Asy/um.

EARLY CHILDHOOD EDUCATION - CHILDREN - HISTORY OF EDUCATION PEDAGOGY

Este texto pretende identificar aspectos da educação das crianças de zero a seis anos, no Asilo dos Expostos da Santa Casa de Misericórdia de São Paulo, de 1896 até 1950. Para tanto, foram consultados os Relatórios dos Mordomos dos Expostos, que eram os administradores do asilo. A primeira data refere-se à transferência do asilo para o bairro do Pacaembu e a segunda, ao último Relatório, encontrado no acervo do Instituto Histórico e Geográfico de São Paulo.

O Relatório do Irmão Mordomo do Asilo dos Expostos era encaminhado ao provedor para, ao lado dos demais departamentos da Santa Casa de Misericórdia, compor a publicação do relatório anual apresentado à mesa conjunta daquela instituição. Em geral, o Relatório da Mordomia era composto por duas partes. Na primeira, o mordomo fazia balanços da trajetória da instituição e prestava contas da movimentação financeira, das crianças institucionalizadas, da manutenção e reformas nos prédios, dos trabalhos nas oficinas, dentro e fora do asilo, de atividades do cotidiano das crianças. Na segunda parte, o médico do asilo ocupava-se das amas, do sistema da roda dos expostos, das doenças e dos óbitos de asilados. Às vezes, anexavam-se relatórios e textos das professoras, da assistente social e de outros.

A mudança do Asilo dos Expostos para um prédio próprio separou-o do ambiente hospitalar, em que as crianças ficavam próximas aos doentes. No mesmo ano, 1896, era inaugurada a Escola Normal da Praça, depois chamada Caetano de Campos, e o jardim-de-infância anexo. As mudanças nas instituições e na organização do Estado, implementadas desde o período monárquico, ganham nova dinâmica no regime republicano.

A educação das crianças, no Asilo dos Expostos, variava conforme a idade. Os bebês até cerca de dois anos, ou em alguns casos até os quatro anos, permaneciam fora do asilo, por meio do sistema das amas-de-leite "mercená- 
rias" - até a mudança da forma de atendimento, em 1936, com a inauguração do berçário. Após a estada com as amas, as crianças eram internadas no asilo. Ali se criou um jardim-de-infância, associado à educação na escola primária, educação que se complementava com alguma formação profissional. $\bigcirc$ texto irá tratar inicialmente, das propostas para os bebês e, posteriormente, das propostas para as crianças de três a seis anos.

\section{A EDUCAÇÃO DOS BEBÊS}

mordomo dos expostos, Guilherme Dumont Villares, que assumiu esse posto em julho de 1936, inicia o relatório relativo àquele ano com a proposta de apresentar os resultados da nova orientação que substituiu o "antigo serviço das amas" pelo "novo" berçário, o "que modificou radicalmente um serviço que datava de mais de um século". O sistema de entrega do bebê "a uma criadeira, para que esta a levasse consigo e em sua própria casa, Ihe prodigalizasse os cuidados que a tenra idade do pequeno exposto estava a exigir" (p. 193), havia sido iniciado em I825, quando a Santa Casa recolheu a primeira criança abandonada.

A mudança do asilo para o prédio próprio, em 1896, teve implicações diretas para as crianças maiores e não para os bebês, que continuaram no mesmo sistema. Entretanto, naquele mesmo ano, um Regulamento para Amasde-Leite, entre outras ações, determinava, como forma de controle em relação aos aspectos de higiene e saúde, que essas tivessem registro junto ao Serviço Sanitário, órgão público responsável pelo saneamento e pelas políticas de higienização do Estado de São Paulo (Almeida, 2003, p. I 8).

Havia uma forte resistência das amas em relação às noções básicas para melhor alimentação, aplicação correta dos medicamentos às crianças, limpeza, entre outras necessidades, fatores que aumentavam os índices de mortalidade infantil. Isso se relacionava à sua formação - a maioria pobre e sem instrução - embora também houvesse casos de negligência por parte delas para com as crianças. Uma das funções do Serviço Sanitário era a de educar, divulgando junto às amas informações para que pudessem cuidar das crianças da melhor forma possível. De acordo com Rocha (2003, p.32), os médicos higienistas representam-se "como porta vozes da razão, do progresso e da modernidade, esses homens de ciência reclamam para si a responsabilidade pelos 
destinos da cidade e de seus habitantes, procurando impor-lhes um conjunto de preceitos que deveria guiar as suas vidas".

Como incentivo às práticas de cuidados e educação dos bebês, criaramse associações para orientar mães pobres e amas-de-leite. $O$ Instituto de Proteção à Infância e Assistência do Rio de Janeiro (Ipai-RJ), entidade fundada pelo médico Arthur Moncorvo Filho, em 1899 , propagou-se por várias capitais do país e difundiu diversos modelos institucionais. Uma das formas de estimular as mães que aleitavam seus filhos foi a promoção de concursos de robustez para bebês, atribuindo prêmios em dinheiro (Kuhlmann Jr., 2004, p.86).

A Santa Casa de São Paulo adotou procedimento semelhante: foi estipulado pela irmandade um prêmio em dinheiro para as três amas cujos lactentes se apresentassem em melhores condições, tendo em vista a pesagem inicial e final e o estado de saúde do exposto sob sua responsabilidade. Em 1905, o prêmio foi de 100 mil réis. Para o segundo e o terceiro lugar, 50 mil réis cada um. A ganhadora foi M.O.B,

...que recebendo uma creança com I kilo 450 grammas, portanto débil ou prematuro estado conseguio, com seus cuidados fazer com que se desenvolvesse muito regularmente, o que é sempre difficil. Com effeito, em 22 de fevereiro a creança recolhida pezava I kilo 450 grammas, em 10 de julho 3 kilos e 900 grammas. (Relatório de 1905, p.68)

Os altos índices de mortalidade não eram atribuídos à qualidade do leite, mas sim às condições de moradia e higiene das amas. Embora fosse possí-

I. A ordem das Santas Casas de Misericórdia, de caráter leigo, foi instituída em Portugal pela Rainha Leonor de Lancastre, no ano de I498, que juntamente com o Rei D. Manuel, assinou compromisso com Frei Contreras (confessor da Rainha), a Infanta Dona Brites e o Arcebispo de Lisboa, D. Martinho da Costa, com os objetivos de: tratar os enfermos, patrocinar os presos, socorrer os necessitados e amparar os órfãos. No Brasil, a primeira Santa Casa foi fundada por Bráz Cubas, no ano de I 543, na Capitania de São Vicente (Vila de Santos). Por volta de 1560, deu-se a criação da Confraria da Misericórdia de São Paulo dos Campos de Piratininga, que esteve alojada no Pátio do Colégio, nos Largos da Glória e da Misericórdia, sucessivamente. A direção da irmandade é exercida pela mesa administrativa, composta por 50 irmãos mesários, e um poder executivo - a provedoria - integrada pelos irmãos: provedor (autoridade máxima), vice-provedor, escrivães, mordomos, tesoureiros e procuradores jurídicos (http://www.santacasasp.org.br). 
vel encontrar um número grande de amas moradoras em bairros mais próximos do centro da cidade, como Brás, Mooca, Pari, muitas habitavam em distritos afastados como Embu, Itapecerica da Serra, Santo Amaro, o que dificultava, em muito, o acesso ao hospital e, mais ainda, o seu controle por parte dos médicos, fiscais e pelo próprio mordomo.

Ao assumir a responsabilidade pelo exposto, a ama deveria retornar à Santa Casa pelo menos uma vez por mês, para que a criança passasse pelo controle médico e para que ela recebesse seu salário. Porém, muitas delas, talvez pelo fato de morarem longe ou mesmo devido à criança não estar bem de saúde, postergavam sua ida à Santa Casa, não cumprindo a determinação. Nesse caso, mordomo, médicos e fiscais iam até suas residências, como pode ser constatado na citação a seguir:

O factor que mais tem prejudicado o serviço de aleitamento dessas crianças residentes fora da cidade é, sem duvida alguma, as distancias que existem entre as moradias das amas, que sem exagero algum podem ser calculadas em algumas dezenas de leguas. Ora, fiscalizar-se de 35 a 40 amas residentes em sítios diversos, numa área tão elevada, levando-se também em conta não só a defficiência de transporte como também as sorprezas que trazem na maioria, é quase que impossível. (Relatório de 1910, p. 104)

Em 1909, de 126 crianças entregues às amas de sítios, 22 faleceram. De 25 aos cuidados das amas da cidade, 12 morreram, relatava em 1912 o médico do asilo, Synesio Rangel Pestana, ao então mordomo dos expostos, João Maurício de Sampaio Vianna. "Embora sejam entregues ás amas da cidade as creanças mais fracas e que pareçam exigir maiores cuidados médicos, é elevadíssima a mortalidade - 50\%". Questionava também se

não devíamos attribuir o facto á fiscalização defeituosa das amas em seus domicílios" [...]

No sentido de permittir uma serie de estudos a respeito das creanças expostas e abandonadas vamos iniciar este anno grande numero de providencias scientificas que nos autorizem a propor varias medidas em beneficio da saúde destes pequeninos seres. [...] Dentre estas, têm chamado particularmente a nossa attenção as que referem ás amas que na sua ignorância ou bondade realizam os 
esforços da puericultura moderna, resumidos na velha phrase do poeta grego "mater est quae lactavit, non quae genuit" [mãe é a que alimenta, não a que gera]. (Relatório de 1912, p.100-101)

Rangel Pestana chamava a atenção para a estatística de mortalidade das crianças sob responsabilidade da Santa Casa, seja por meio do asilo ou das amas. De 1909 a 1912 , de um total de 652 crianças, houve 178 óbitos. E fazia uma comparação: "Ao passo que em 1912 a porcentagem de óbitos de creanças de 0 a I anno, em toda Capital foi de 19,9 por 100 nascimentos, nós registramos 28,5 por 100 entrados" (Relatório de 1913, p.88). Seguia comentando que:

A maioria dos óbitos se verifica nos lactantes entregues ás amas dos sítios, creaturas inteiramente ignorantes do que seja hygiene alimentar. [...] há ainda a falta de medico no logar, o que obriga as amas a consultarem os curandeiros boçaes da redondesa [...]. Os óbitos occorridos nos sítios trazem todos attestados de pessoas idôneas do logar ou do escrivão do registro civil de Itapecerica. Dos fallecidos durante o anno de 1912 só 9 viviam nesta Capital sendo os 4 I restantes dos sítios. (1913, p.88)

Em 1929, o médico Synesio Rangel Pestana afastou-se do cargo. Em seu lugar tomou posse João Leite Bastos Júnior, que já exercia o cargo como adjunto. Em seus relatórios mantinha a mesma preocupação quanto aos elevados índices de mortalidade das crianças junto às amas-de-leite. No ano de 1933 , Leite Bastos solicitava a transferência das crianças menores de dois anos que estavam em poder das amas, inclusive com a construção de um local adequado para atendê-las. Justificava seu pedido dizendo que:

...esse doloroso confronto entre a elevada lethalidade das crianças confinadas ás bondosas mas incultas caboclas de Itapecerica, e a mortalidade nulla das que ficam sob os cuidados das virtuosas e dedicadas Irmãs de São José, está aclamar por providencia urgente e definitiva que ponha os lactentes em situação de igualdade á de outros expostos. [...] Esta providencia importa, inicialmente, na construcção de um pavilhão para menores de 2 annos, onde esses infelizes possam receber os benefícios da moderna hospitalização. Aconselhado pelos profícuos resultados obtidos no país e no extrangeiro. (Relatório de 1933, p.28I) 
Marcílio (1998, p.249) comenta que "sempre, e em todo lugar, se pagavam salários irrisórios às amas-de-leite de expostos. E isso foi dado como causa da pouca atenção e dos parcos cuidados das amas para com os bebês expostos". As condições precárias das amas, assim como a baixa remuneração recebida por elas, eram preocupações constantes dos responsáveis pelo asilo. Tanto assim que, em relação a 1936, o então mordomo Guilherme Dumont Villares afirmava que:

...essas criadeiras ou amas que assim se chamavam, eram mulheres de origem modesta, as quaes, residindo nas vilas mais pobres dos arredores da Capital, ao receber a creança em sua casa, não visavam senão uma remuneração, por pequena que fosse. E era, de facto, das mais modestas a que a nossa Instituição Ihes dava por tal serviço [...]. Nessas condições, é bem de ver-se, havia de ser das mais rudimentares a assistência que taes "amas" poderiam prestar as creanças que perfilhavam [...]. Assim, por mais que fosse a bôa vontade que algumas revelavam, a precaridade das condições materiais impossibilitava uma conveniente assistência á creança exposta, que em geral pagava com a vida a ausência das attenções com que a moderna pediatria consegue, em certos paizes, reduzir a um mínimo a cifra da mortalidade infantil. (Relatório de 1936, p. 194).

Nota-se na leitura dos relatórios da mordomia a necessidade, cada vez mais forte, da Santa Casa e do próprio mordomo, de modificar o serviço das amas, uma vez que detectavam, pelo controle mensal, a precariedade das condições físicas das crianças criadas por elas. "A falta de cultura e de recursos materiaes das pobres amas as impedia completamente de executar as regras que Ihes eram ensinadas pelos médicos" (Relatório de 1936, p. 195).

Segundo o mordomo Guilherme Dumont Villares, o berçário começou a funcionar em 20 de outubro de 1936, em uma casa alugada na rua Frederico Steidel, I57, bairro de Santa Cecília.

A principio, installámos algumas que tínhamos levado provisoriamente para a nossa residência particular, afim de evitar que fossem para as casas das amas; depois, aquellas que por esses dias foram expostas na Roda e nos chegaram de outras procedências; a seguir, retiramos todas as creanças que estavam com as 
amas: - e assim fomos pondo em funccionamento o novo Berçário. (Relatório de 1936, p.197)

Paralelo à instalação do berçário, foi criado também um lactário, com finalidade "médico-social" - uma forma de restringir, ao que parece, o serviço das amas pois, de acordo com o próprio mordomo, a finalidade do mesmo é "extrahir, conservar e distribuir leite humano a débeis, prematuros e doentes, expostos ou filhos de ricos e pobres, evitando-se assim, ao mesmo tempo, os inconvenientes irremediáveis do aleitamento mercenário" (Relatório de 1936, p.200).

Lívia Vieira (1988, p. I0), em artigo sobre o Departamento Nacional da Criança, conta que, em 1938, Vasconcelos e Sampaio propunham dois tipos de instituição para socorrer as crianças pobres e combater as criadeiras: "Os lactários, que alimentam as crianças e ensinam as mães, servem às mulheres que podem guardar junto de si os filhos; e as creches, de depósitos: para as mulheres que são forçadas a trabalhar". No Relatório da Mordomia de 1938, verifica-se que o papel das amas se modificou: "De nutriz mercenária que era, qualificativo aviltante e desprezível, passou a ser doadora de leite, funcção altamente humanitária, conforto de mães que soffrem e salvação de criancinhas que fenecem" (p.275).

O relatório de 1936 trouxe oito fotos do berçário e duas da Chácara Wanderley, onde funcionava o asilo. Na supervisão do berçário, Guilherme Dumont foi auxiliado por sua esposa Maria Luiza Villares e pelos médicos Leite Bastos e Wladimir Piza. A casa, administrada por Maria Célia Bonilha, contava com seis enfermeiras, seis pagens, duas cozinheiras e uma ajudante, uma roupeira, uma chefe de lavanderia, três lavadeiras, duas passadeiras, uma pessoa para limpeza da casa, uma costureira e um jardineiro:

Devemos também consignar aqui o inestimável auxilio prestado por algumas senhoras, que altruisticamente se interessam pelas creanças, trazendo nos diariamente ajuda preciosa do seu trabalho. A estas abnegadas companheiras, os nossos melhores agradecimentos. (p. 201)

Nos dormitórios, com capacidade para 60 crianças, havia livros de enfermagem, em que se anotavam, diariamente, todas as informações sobre a 
saúde de cada criança. "A temperatura é tomada de manhã, e à noite, e qualquer normalidade em diurese, dejecções, vômitos, alimentação está também registrada para informação medica." (p. 198).

Mas a preocupação não era exclusiva com os problemas de ordem médica, como pode se observar:

Os serviços do Berçário, onde as creanças permanecem até os tres annos de idade, continuam muito bons, tendo-se conseguido resultados realmente extraordinários não só na saúde das creanças como no seu desenvolvimento mental. [...] Pelo lado psychico, também, essas creanças, cuidadas por boas auxiliares, que, com carinho e affecto, realmente se interessam pelo seu bem estar, permittindo o desenvolvimento normal de sua mentalidade - conservando-lhe a alegria e a individualidade própria - apresentam os melhores resultados. As creanças nesta casa tem a mesma alegria e a mesma mentalidade de creanças criadas nas casas das nossas melhores famílias. (Relatório de 1938, p.257-258)

A princípio, a iniciativa da implantação do berçário deu resultados positivos. Tanto que, em reunião da Mesa Administrativa de 5 de dezembro de 1941, foi aprovado parecer da Comissão de Contas e Obras "favorável à autorização para os estudos e elaboração de plantas e orçamento para a construção de um prédio anexo ao Asilo Sampaio Vianna para servir de berçário" (Relatório de 1941, p.98).

Em I/I/I 943 havia 59 crianças no berçário. Entraram, durante o ano, 29, faleceram I I, saíram 28. Em 31//2/1943, havia 49 crianças: duas foram removidas para a Escola Pacheco Silva, seis, para o asilo, dez entregues mediante tutela, nove entregues ao pai ou mãe e uma, ao juiz de menores (Relatório de 1943, p.234).

Há um inventário do berçário referente ao mês de agosto de 1943. Entre outros objetos que podem ser indícios de uma ação pedagógica estão: duas estantes grandes para brinquedos, duas estantes pequenas para brinquedos, um rádio, uma vitrola quebrada, três quadros, "diversos brinquedos" (não especificam quais) e um espelho (p.272).

Em 1945, o berçário foi transferido para a antiga enfermaria do asilo:

....depois de inteiramente remodelada, adaptada e modernizada, veio contribuir decisivamente para uma melhor e mais fácil orientação de trabalho pela unifica- 
ção da administração e dos serviços médicos e de enfermaria. [...] Estão realmente melhor assistidas crianças de primeira idade, 0 a 3 anos com maiores instalações da cozinha dietética e refeitório anexo, os novos banheiros dotados de todo conforto, tendo concorrido para a implantação de hábitos higiênicos e de educação. Sendo que todas as despesas realizadas com as reformas foram custeadas com o generoso donativo oferecido á nossa Irmandade pela São Paulo Companhia Nacional de Seguros. (Relatórios de 1945, p.25 I)

\section{A EDUCAÇÃO NO JARDIM-DE-INFÂNCIA}

No ano de 1904, o mordomo João Maurício de Sampaio Vianna organizou a escola do asilo em três seções, a primeira, com 59 alunas de cinco a 14 anos, a segunda, com 46 alunos de seis a 12 anos:

N'estas duas secções o ensino adoptado é calcado no programma official, e folgo em confessar que, tanto os alumnos da primeira como os da segunda secção, demonstraram, no correr do anno grande aproveitamento.

A terceira secção que não é mais do que um ponto de reunião de creanças um grande jardim de infância, teve uma freqüência de 16 creanças, regulando as edades de 3 a 5 annos. (Relatório de 1905, p.64)

Mas é a partir da década de 1940 que há mais informações sobre o sistema de ensino e as educadoras, as metodologias, a estrutura física das salas e as disciplinas, entre outras notícias da escola no asilo e de seus alunos. Por meio de um extenso relatório, no do ano de 1943, foi possível compreender meIhor e com maiores detalhes a prática educacional vivenciada pelas crianças institucionalizadas. Naquele ano, 86 alunos estavam no ensino primário, 46 meninos e 40 meninas, e no jardim-de-infância, 29 crianças (p.236).

Quanto ao lazer das crianças, vale a pena observar uma foto que mostra as crianças uniformizadas, calçadas e algumas delas até penteadas, brincando no jardim do asilo. Nota-se um grupo de crianças que, apesar de não estarem brincando com os triciclos, patinetes ou cavalinhos de madeira, aguardavam - alguns até em fila - sua vez de brincar. Sugere-se que esse era o "combina- 
do" entre as crianças e os responsáveis pela brincadeira ou, quem sabe, alguém controlasse o tempo das crianças nos brinquedos.

A partir de 1943, o jardim-de-infância do asilo passou a contar com a colaboração da professora Alice Meirelles Reis, que organizou as duas classes, doou um "museu" completo e indicou duas de suas alunas para o cargo de professora. Num extenso relatório as professoras Vera Castanho e Renata Colombo discorriam sobre seus trabalhos.

Nas linhas iniciais reclamavam do comportamento dos alunos. "Fomos assaltadas por grande desânimo diante da indisciplina e falta de bons hábitos de algumas crianças". Porém, segundo elas, com a retirada dos alunos mais problemáticos e apoiadas que foram pelas Irmãs, "conseguimos, não tanto como pretendíamos, mas melhorar não só a disciplina como a formação de bons hábitos sociais e morais" (Relatório de 1943, p.259).

De acordo com o mesmo relatório de 1943, as aulas começaram no dia $I^{\circ}$ de julho. Na classe masculina, 20 alunos, com idade entre três anos e meio a sete; na feminina, 18 alunas, com a mesma idade. Naquele primeiro dia, por causa da indisciplina e desobediência, "não foi possível organizar qualquer atividade" (p.260). Foi necessária a presença da pajem para que pudessem ensinar como formar uma fila ou mesmo sentar. "As crianças maiores se consideravam superiores e molestavam em grande parte a turma dos menores. Com a retirada destas, consegui daí por diante, dar algumas atividades organizadas" (p.260).

Em seus escritos, as professoras, ao relatarem cada atividade ministrada, escreviam uma observação. Assim, em relação ao desenho, segundo elas, consistiram "em garatujas e mais tarde, objetos conhecidos" (p.26I). Na observação, colocaram que essa atividade sempre foi recebida com alegria por parte das crianças, "sendo um castigo não deixa-las desenhar" (p.26I).

Há também algumas observações assinaladas no mesmo relatório, em relação às crianças e à escola/infra-estrutura. Segundo as professoras, em termos de higiene, as crianças estavam "bem observadas, roupa simples e asseiada; falta de calçados para a classe masculina". Sobre o refeitório, "pouco agradável e não apropriado". Em relação às instalações sanitárias, "apropriadas e com pouco asseio". Caracterizaram ainda o recreio como "saudável (ar livre), espaçoso, com aparelhos para movimento, escorregador, balanço, tanque de areia" (p.259). 
Quanto à linguagem, "péssima, quanto aos termos e à pronúncia". Para melhorá-la, foram utilizados os seguintes meios: correção dos defeitos da linguagem em todas as oportunidades; deixar a criança falar, ouvir e conversar; palestras; dar o nome apropriado para o material; histórias contadas e repetidas pelas crianças com auxílio de perguntas; memorização de pequenas poesias (p.26l).

Em relação a outras atividades desenvolvidas, citaram canto, jogos organizados, exercícios sensoriais (de atenção, cores, formas e raciocínio) e hábitos de ordem. "Conseguimos os hábitos de ordem, aproveitando todas as oportunidades como escolher, brincar e guardar material, formar a fila etc." (p.262). Sobre os trabalhos manuais há informações mais detalhadas de como eram feitos. De acordo com as professoras as atividades eram:

a) enfiar contas, apreciado pelas meninas; b) construção de blocos, apreciado pelos meninos, c) construção na areia, agradava ambas as classes, d) dobraduras - muito simples porque as crianças encontravam dificuldades; e) modelagem, muito apreciada; f) recorte e colagem de gravuras - muito apreciado; g) alinhavo - muito apreciado e era dado somente para os maiores; havia grande facilidade por parte das meninas; h) pintura, grande interesse; e os desenhos eram grandes e simples. (p.26I)

Na observação relatavam que a construção na areia proporcionava grande indisciplina, pois as crianças atiravam areia umas às outras. "Foi necessário retirar algumas do brinquedo e deixa-las à parte" (p.26l). As aulas de canto, acompanhadas de piano, eram ministradas três vezes por semana no salão de festa. De acordo com o relatório,

...agradava muito às crianças e a aprendizagem era fácil . Segundo as professoras, nos dias em que não havia canto no salão de festas, havia em classe, rodas com canto, cantos e marchas cantadas. Na classe masculina, as rodas com canto eram dadas com grande dificuldade porque várias crianças se recusavam a participar dessa atividade. As aulas de canto eram mixtas. (p.26l)

Pela primeira vez há informações que caracterizavam fisicamente a sala de aula. No relatório de 1943 descreviam que era "apropriada, espaçosa, cla- 
ra, arejada (4 janelas) e com pouco asseio" (p.260). Destaca-se a observação final escrita pelas professoras:

Procuramos sempre evitar que as crianças mentissem, aconselhando-as e apelando para a religião. Quanto à delação, em todos os casos fizemos com que a própria criança culpada se acusasse, e havia sempre repreensão momentânea. As crianças tinham também o grande defeito de brigar e essas eram afastadas das outras, tanto na classe como na fila. Para qualquer questão que surgisse na classe, procuramos saber as razões de ambos os lados para depois fazer a devida justiça. (p.263)

Fica uma dúvida em relação à "devida justiça". Isso porque não há, nem mesmo nas entrelinhas dos relatórios, alguma atitude que nos levasse a pensar que eram empregados castigos físicos ou maus-tratos aos asilados como forma de punição. Daí não podermos concluir que tal expressão deva tratarse de algo deste tipo.

Nas declarações constantes nos relatórios das professoras, de 1943, verificam-se passagens em que essas chamam a atenção para a indisciplina, o atraso na linguagem, para a carência de calçados em algumas crianças e até mesmo para a falta de higiene em determinados locais da escola, como os sanitários. Essas observações contrariam, de certa forma, a lógica do enaltecimento que supostamente utilizaram ao escreverem os relatórios ao mordomo. Talvez essa atitude tenha a ver com o fato de estarem iniciando seus trabalhos naquele ano, excluindo-se assim de qualquer responsabilidade pelos aspectos negativos encontrados. Pode ser também que sinalizassem para os responsáveis superiores que a situação encontrada exigiria delas um grande esforço no sentido de revertê-la.

A saída das Irmãs de São José do asilo ocorre em 19 de julho de 1944. No mesmo dia, Branca Leite de Mello, que havia ingressado um mês antes na direção do berçário, assume a direção do asilo, comissionada pelo governo do estado (Relatório de 1944, p.242). No Relatório de 1944 nota-se o entusiasmo do mordomo quanto aos resultados alcançados no jardim-de-infância. Segundo ele, com o excelente trabalho desenvolvido pela professora Alice Meirelles Reis, houve uma "notável transformação nos nossos internados, imprimindo-Ihes as primeiras noções de civilidade, bons costumes, boas maneiras e hábitos de higiene" (p.243). 
No início daquele ano foi introduzido o curso de "ginástica educativa e corretiva", cujo objetivo principal era o de corrigir "defeitos" observados na constituição física de muitas crianças e também na "expansibilidade de movimentos, despertando o interesse associativo da ginástica moderna de marchas, ritmos e jogos" (p.245). A professora Cordelia Barbosa Dalpino relatou que para as crianças do jardim-de-infância eram ministradas aulas com exercícios imitativos, aula historiada e pequenos jogos amenizados com "cantos, rodas cantadas e recitativos" (p.262).

No ano de 1944 foi inaugurada a Casa de São José, localizada na Alameda Barão de Limeira, tendo posteriormente sido transferida para a Avenida Angélica. Foi criada especialmente para abrigar as asiladas que, por motivo de indisciplina e idade, não poderiam continuar no Sampaio Vianna. O relatório de 1945 traz um balanço do ensino ministrado no interior do asilo e seus resultados, pelo menos de forma parcial. Nesse sentido, após a mudança das meninas para a Casa de São José ficaram no Asilo Sampaio Vianna somente crianças menores de 12 anos. Sendo que até quatro anos havia asilados de ambos os sexos. A partir dessa idade, exclusivamente meninos.

As aulas de educação física, segundo o relatório, tornaram as crianças mais fortes, sadias e alegres, "contribuindo para um desenvolvimento acima do normal”. O programa do jardim-de-infância masculino, desenvolvido pela professora Lirba de Barros Esteves, conseguiu "desenvolver o espírito das crianças, educando-as com suavidade e atenção individual e imprimindo a todas gradativamente bons hábitos de higiene e educação" (Relatório de 1945, p.252).

Terminado o jardim-de-infância, "os meninos vão para o Grupo Escolar do bairro, medida esta das mais salutares introduzidas desde 1943". Segundo o relatório, os resultados dos estudos feito no grupo são aqueles:

...comuns de todas as crianças, mas o desenvolvimento associativo, o conhecimento das coisas externas, a vida em comum nas classes, o trajeto para o Grupo com as suas naturais intercorrências, criam para cada criança uma confiança em si própria, com os meios de defesa e de adaptação tão necessários sobretudo aos que como os nossos, não contam com o amparo de seus Paes ou de suas famílias foi incontestavelmente a realização desta parte de nosso programa uma das maiores compensações que tivemos na trabalhosa Mordomia do asilo. (Relatório de 1945, p.252) 
O jardim-de-infância feminino, dirigido pela professora Renata Colombo, tinha como princípios "educar pela persuasão, com bondade e com o objetivo sempre presente da formação de bons hábitos e do caráter e personalidade da menor, criando horror á mentira, á delação e á hipocrisia" (p.253).

O programa era baseado nos centros de interesse, método criado e desenvolvido pelo médico e educador Ovide Decroly. O método consistia em idéias geradoras como: necessidade de alimento, luta contra intempérie, necessidade de defesa, necessidade de ação e de trabalho (Kishimoto, 1988, p. I19).

O conceito de interesse é o "pontapé" inicial da teoria de Decroly. Segundo o educador, a necessidade gera o interesse e só este leva ao conhecimento. Herbart, um dos pedagogos no qual Decroly se inspirou para elaborar suas teorias, dizia que o "interesse liga-se aos próprios objectos; é involuntário e precede a eclosão do 'desejo' que desencadeia o acto” (Bassan, 1978, p. 19).

Segundo escritos da professora Lirba de Barros Esteves, uma vez captado o interesse, é elaborado um projeto com as atividades que poderiam vir a solucionar o problema trazido pelo asilado:

Tudo o que é dado no Jardim parte do interesse da criança, logo, é ela que nos dá o seu problema e nós vamos desenvolve-lo de acordo com a sua idade. [...] No desenvolvimento destas atividades, as crianças irão aplicando os conhecimentos adquiridos, comparando-os com os conhecimentos anteriores e adquirindo experiências novas. (Relatório de 1945, p.259)

Ainda de acordo com a professora, naquele ano foram desenvolvidos, com os meninos, seis centros de interesse, e os temas foram trazidos pelas próprias crianças: "os animais", "meios de transporte”, "o galinheiro", "as plantas", "a Arca de Noé" e o "presépio". Segundo ela, o projeto que mais agradou e no qual houve maior colaboração das crianças foi "o galinheiro" (p.259).

Nas atividades ministradas ao longo do ano, havia jogos livres e organizados, estudo da natureza e vida social, exercícios sensoriais, dramatização, trabalhos em grupo, entre outras. Apontavam-se três problemas: a indisciplina, a falta de interesse das crianças e a existência de alunos com três anos de idade misturados com os de seis anos, que eram a maioria. De acordo com a professora, as crianças de três anos tinham necessidade contínua de movimento e perturbavam as atividades dos maiores. Ela terminava seus escritos com um 
questionamento: "Uma vez que há número suficiente de alunos porquê permitir na classe, crianças de três anos?" (p.26l).

No jardim-de-infância feminino, naquele mesmo ano de 1945, as atividades também foram desenvolvidas com base nos centros de interesse. Segundo a professora Renata Colombo, o maior problema quando as crianças estavam no asilo era a falta de interesse. Com a transferência para o Lar São José, essa atitude modificou-se:

Nós precisávamos despertá-lo nelas; por nada se interessavam, não traziam problemas para a classe; isso porem desapareceu com a vinda das crianças para o lar, vinda essa que não trouxe somente este benefício, trouxe também outro de importância muito maior, fez com que as crianças se sentissem em sua própria casa; viver como se estivessem entre seus pais; isso observei na casa de boneca nas dramatizações. [...] vi dramatizações de cenas diárias como: o aniversário da boneca, a boneca está doente, a vinda do médico, a visita de uma amiga; as meninas vão à cozinha fazer o bolo, fazer o café etc. etc... (p.265)

Ainda de acordo com o relatório da professora, em 1945 foram desenvolvidos três centros de interesse: "o gato", "a primavera" e o "presépio". Para ela, "a primavera" foi o melhor projeto desenvolvido e que contou com o maior interesse pelas crianças.

Os centros de interesse deveriam ser grupos de aprendizado organizados de acordo com a faixa etária dos alunos. $\bigcirc$ desenvolvimento das atividades proporcionava "o ajustamento da criança ao grupo social, a acquisição de novas técnicas de trabalho e a formação de bons hábitos" (p.259).

A opção por esse método, provavelmente, estava relacionada com a presença da professora Alice Meirelles Reis que, a partir de 1943, atendeu convite dos responsáveis pelo asilo e organizou duas classes do jardim-de-infância, e contou para isso com o trabalho de duas de suas alunas: as professoras Vera Castanho e Renata Colombo. Docente do jardim-de-infância anexo à Escola Normal Caetano de Campos de 1922 a 1940, Superintendente de Ensino de Departamento de Menores Abandonados da Liga das Senhoras Católicas, entre 1934 a 1940, e assessora técnica, nomeada pelo governo, de instituições assistenciais que tivessem educação infantil - como era o caso do 
asilo - Alice Meirelles Reis teve influência em seu trabalho do educador Decroly (Kishimoto, 1988, p.123). Ela foi também "auxiliar de presidente", em 1932, na composição da primeira diretoria do Centro de Estudos e Ação Social, entidade que foi a fundadora e mantenedora da Escola de Serviço Social. Em 1937 passou a fazer parte do conselho técnico desta mesma escola (Yasbek, 1977, p.27 e 44).

Os responsáveis pela casa estavam bastante satisfeitos e, em resolução da Mesa Administrativa de 20 de maio de 1944, "foi resolvido agradecer à Professora Alice Meirelles Reis a sua efficiente collaboração na reorganização do Jardim de Infância do Asylo Sampaio Vianna" (Relatório de 1944, p.27).

A partir do ano de 1948 o Asilo Sampaio Vianna passou a contar com um curso maternal, com 18 crianças, cuja professora, Olinda Pinto de Miranda, foi cedida pela Secretaria da Educação. O objetivo desse curso, articulado com o jardim-de-infância, segundo os responsáveis pelo asilo, era o de dar aos préescolares hábitos que melhorassem suas condições físicas, morais e sociais, de modo a fornecer-lhes uma base mais sólida para quando ingressassem no período verdadeiramente escolar (Relatório de 1948, p.258).

Segundo o mesmo relatório, 23 crianças que freqüentaram o curso primário tiveram o apoio da professora Orsina Seabra Leal "como auxiliar no preparo das lições". No jardim-de-infância, "que é parte preponderante nas nossas atividades", estudaram, no período, 19 crianças, sob a responsabilidade da professora Lirba de Barros Esteves. Também houve na capela do asilo a primeira comunhão de oito meninos, sendo que as aulas de catecismo foram ministradas semanalmente, com a colaboração da professora Olinda Pinto de Miranda (p.26I-2).

O último relatório relativo à educação no interior da instituição data de 23 de fevereiro de 1950, escrito pela professora Lirba de Barros Esteves e encaminhado ao mordomo, na época, João Leite de Bastos. Nele há uma descrição das atividades trabalhadas ao longo do ano anterior. A maioria dos alunos tinha quatro anos e, percebendo que as crianças necessitavam de exercícios nos quais pudessem se "movimentar à vontade", a professora organizou um programa com aulas de ginástica recreativa, jogos livres, jardinagem, passeios ao redor do asilo e do Estádio do Pacaembu, além de brincadeiras com bola, bicicleta, patinetes e carros para puxar. "As histórias foram curtas e cheias de repetições; as palestras ligeiras, pois as crianças nessa idade não têm atenção 
fixa". A adaptação dos alunos novos ao jardim-de-infância não constituiu problema, segundo ela. "Apenas o José Alberto (Pimpa) recusava-se a deixar sua cadeirinha para as atividades organizadas" (Relatório de 1949, p.212).

Estiveram também num circo, tendo o passeio resultado no centro de interesse "o circo". De acordo com a professora, o ano foi encerrado em meio a grande alegria com a festinha de Natal "e a minha satisfação foi imensa por ficar ciente de que o ano de 1949 fôra proveitoso para as crianças" (p.212).

\section{CONCLUSÕES}

As práticas educativas na história das instituições para as crianças pobres são quase uma incógnita. Quanto às concepções educacionais, as pesquisas sobre a história da educação infantil têm evidenciado que as propostas para essas instituições tratam a pobreza com preconceito. Entretanto, esse preconceito em relação à pobreza não pode ser entendido simplesmente como uma atitude conspirativa, pois se associa a concepções pedagógicas que existiam para as crianças que não se encontravam em situação de pobreza, e que podem ser entendidas atualmente como autoritárias ou disciplinadoras. Quanto às propostas e às práticas educacionais cotidianas, ainda há muito a se investigar sobre elas, para que se possa conhecer melhor o que acontecia nas instituições e o seu efeito sobre as crianças. As evidências dessas práticas são sugeridas, boa parte das vezes, nas entrelinhas dos textos. Para a composição desses fragmentos em uma interpretação consistente são necessárias a busca, a sensibilidade e a oportunidade de encontrar fontes que forneçam esses dados.

No estudo realizado, observa-se que, por um intervalo de aproximadamente 40 anos, poucas informações puderam ser obtidas, relacionadas ao que ocorria com as crianças, com exceção da crítica ao encaminhamento às amas. As avaliações apresentadas, quando da implementação das novas propostas, que começam a acontecer a partir da inauguração do berçário, em 1936, e daquelas ocorridas a partir do início da década de 1940, no jardim-de-infância, sugerem que até então a educação oferecida era de muito pouca qualidade.

A saída das Irmãs de São José, do berçário, em 1944, culmina um processo de transição para profissionais laicos, encarregados do trabalho educacional. Entretanto, isso não significa a retirada dos conteúdos religiosos, que pode ser identificada na denominação da Casa de São José, inaugurada na 
mesma data, assim como nas referências às aulas de catecismo e ao uso da religião como forma de persuasão para obter disciplina.

No que se refere à educação das crianças pequenas, obter informações sobre as propostas e as práticas educacionais é ainda mais difícil do que para a criança de sete anos ou mais. Quanto menor a idade das crianças, mais esses dados se diluem. Mesmo nos dias de hoje, é comum a demanda de profissionais da educação infantil, relacionada às poucas orientações para a educação e os cuidados das crianças dos zero aos dois ou três anos. As propostas e os modelos de cuidado e educação dos pequenos circulam intensamente nas próprias práticas, transmitidas dos "experientes" aos "iniciantes". Esses conhecimentos, por vezes, são propostos de forma mais sistematizada nos manuais e nos cursos de puericultura organizados por médicos para as mães e para as professoras. A educação dos pequenos ocorre diretamente associada aos cuidados prestados a eles e os preceitos não são exclusivamente de ordem médica ou higiênica, mas evidenciam concepções sociais e educacionais. Na história do Asilo da Santa Casa, a criação do berçário sinaliza a opção pelo modelo da instituição educacional coletiva, com um corpo profissional, em oposição ao modelo doméstico.

Quanto às crianças maiores, as práticas são mais explicitadas no período posterior a 1940. A chegada de profissionais ligados ao sistema público de educação estadual e as suas propostas pedagógicas revelam a sintonia com as concepções educacionais daquele período. Mas as crianças de três anos, já fora do berçário, parecem ter ficado um tanto à margem no interior da turma do jardimde-infância, até a abertura do maternal, em 1948. Observa-se a dificuldade das professoras em organizar atividades para esse grupo, ao lado dos maiores, relacionada a uma expectativa do comportamento disciplinado das crianças, seguindo filas e permanecendo quietas, sentadas, em seus lugares. Daí se consideravam os pequenos como indisciplinados e indicava-se como solução a sua retirada da classe, da mesma forma que a outras crianças maiores, que apresentassem comportamento mais irrequieto ou com necessidades especiais.

Cabe destacar a presença de práticas pedagógicas oriundas da longa tradição das propostas de Froebel para o jardim-de-infância, relacionada às atividades de recortes e colagem, de alinhavo, de construção com blocos, nos trabalhos manuais. Identifica-se uma certa orientação diferenciada para meninos e meninas - estas com "preferência" pelos alinhavos, aqueles pela construção 
com blocos -, o que se distancia das propostas de Froebel, que sugeria atividades comuns para meninos e meninas, e revela uma distinção de gênero incentivada pelas próprias professoras.

Outra fonte de inspiração pedagógica associava-se à proposta dos centros de interesse de Decroly. Cabe destacar a avaliação feita pelas professoras, sobre a "falta de interesse" das crianças, quando comentavam justamente o uso dessa metodologia. A opção pelos temas parece ter surgido mais da vontade dessas educadoras do que propriamente dos interesses das crianças, o que também indica a sua vontade de encontrar atividades que fossem significativas. Isso evidencia ainda a impossibilidade de se isolar as crianças da sua relação com os adultos quando se quer entender as práticas realizadas nas instituições educacionais, mesmo quando elas anunciam uma suposta independência das crianças. Afinal, não se pode deixar de lado a dimensão das interações etárias entre as diversas classes de idade, entre adultos e crianças, e mesmo que se ofereça a elas a oportunidade de escolhas, estas sempre irão ocorrer em espaços planejados e organizados pelos adultos e com materiais escolhidos por eles, em contextos históricos específicos.

O Asilo dos Expostos é marcado pelo seu caráter de instituição total, para utilizar o conceito de Goffman (|96|). Ali, as crianças cresciam separadas de uma referência doméstica familiar. Esse caráter de internamento conjuga diferentes funções e é um dos fatores que levou à interpretação histórica que identifica imediatamente as casas de expostos com as instituições de educação infantil para as crianças pobres como assistenciais. Mas, se a constituição das instituições sociais e a definição das suas funções (assistenciais, educacionais etc.) ocorre no processo histórico de estruturação do Estado e de formulação das políticas sociais, cabe considerar que a influência ocorre no sentido inverso: não é a necessidade de assistência a crianças abandonadas que promove a criação das instituições de educação infantil, mas são as propostas e as concepções pedagógicas existentes na sociedade que se manifestam nas funções educacionais dos internatos.

\section{REFERÊNCIAS BIBLIOGRÁFICAS}

ALMEIDA, M. República dos invisíveis. Emílio Ribas, microbiologia e saúde pública em São Paulo (|898-19|7). Bragança Paulista: Edusf, 2003. 
BASSAN, V. J. Como interessar a criança na escola: a noção dos centros de interesse em Decroly. Coimbra: Almedina, 1978.

GOFFMAN, E. Manicômios, prisões e conventos. São Paulo: Perspectiva, 1961.

KISHIMOTO, T. M. A Pré-escola em São Paulo, 1877 a 1940. São Paulo: Loyola, 1988.

KUHLMANN JR., M. Infância e educação infantil: uma abordagem histórica. 3.ed. Porto Alegre: Mediação, 2004.

MARCílIO, M. L. História social da criança abandonada. São Paulo: Hucitec, 1998.

RELATÓRIO do Irmão Mordomo dos Expostos. In: IRMANDADE DA SANTA CASA DE MISERICÓRDIA DE SÃO PAULO. Relatório [anual]. São Paulo: I 901/1949.

ROCHA, H. H. P. A Higienização dos costumes, educação escolar e saúde no projeto do Instituto de Higiene de São Paulo (1918-1925). Campinas: Mercado de Letras, 2003.

ROCHA, J. F. T. Práticas sociais e pedagógicas no Asilo dos Expostos da Santa Casa de Misericórdia ( 1896-1950). Itatiba, 2005. Dissert. (mestr.) USF.

VIEIRA, L. M. F. Mal necessário: creches no Departamento Nacional da Criança (19401970). Cadernos de Pesquisa, São Paulo, n.67, p.3-16, nov. 1988.

YASBEK, M. C. Estudo da evolução histórica da Escola de Serviço Social de São Paulo no período de 1936 a 1945. São Paulo, 1977. Dissert. (mestr.) PUC-SP.

Recebido em: maio 2006

Aprovado para publicação em: junho 2006. 